\section{Church and State at odds}

POLAND's controversial "Agricultural Foundation", established three months ago under the patronage of the Roman Catholic Church to assist the recovery of private agriculture, is now working out a programme of ten pilot projects, ranging from milk production to tractor repairs, and from water development to agricultural field services. But there are growing doubts about the foundation's effectiveness, depending as it does both on a massive injection of Western capital and on good relations between Church and State.

Uniquely in the socialist bloc, some 75 per cent of Poland's agricultural land is in private hands, in the form of peasant smallholdings, most of which are far smaller than the 15-20 hectares that the UN Food and Agriculture Organization considers the smallest viable size in Northern Europe. Moreover, almost three decades of underinvestment and an artificial price structure that favoured the state sector have resulted in the gradual run-down of agriculture, although in 1980 the constraints on individual farmers were relaxed, and legislation introduced guaranteeing them security of tenure, thereby increasing their incentive to improve their holdings.

At the same time, several rescue operations for agriculture were proposed, including a project by the US Rockefeller Foundation that would have included significant support for the state sector. In the event, it was the Church's proposal, aiding the private sector only, which was adopted. This foundation hopes to raise some $\$ 1,800$ million of external aid over five years; it will purchase external supplies with hard currency raised in the United States and Western Europe, and sell them to farmers at prevailing market prices, partly on a deferred-payment basis. These sales will eventually establish a zloty fund to be used to finance such in-country investments as artesian wells, and also to establish a social infrastructure in rural areas to help halt the drift of young people away from the land.

As yet there is no guarantee that the Agricultural Foundation will in fact receive sufficient backing from the West, and there are fears that the foundation will provoke much argument between Church and State for very little return. Although the land belongs to the farmers, water resources, for example, belong to the state. And although there is a free market in many agricultural products, there is no free market in grain, all of which must be sold to the state at fixed prices. Moreover, the foundation plans not only to provide farm machinery, but to establish a service infrastructure for the machinery.

Scepticism about the foundation comes also from agricultural academies and colleges - largely through ignorance of the foundation's plans. This is unfortunate, since once the foundation becomes operative, as now seems likely, extension courses to teach the farmers to make the best use of their resources and some kind of consultancy service will undoubtedly be necessary.

\section{United States and UNESCO}

\section{Washington}

THF new year starts with still no clear indications of what institutional arrangements will be made to allow the United States continued participation in the scientific programmes run by the United Nations Educational, Scientific and Cultural Organization (UNESCO). US withdrawal from the organization took effect from 1 January. A budget proposal for programmes to replace those of UNESCO has been sent by the State Department to the White House Office of Management and Budget, and details of the President's proposals will be released together with general budget figures later this month. These programmes will not, however, start until October 1985, and some extra stopgap support may be needed until then. Furthermore, in spite of the State Department's "commitment in principle" to diverting the annual contribution saved from UNESCO into development, it now seems unlikely that the full $\$ \mathbf{4 7}$ million per year saved will be spent in this way.

A report on UNESCO's science programmes by the US National Research
Council has suggested that specific support through Funds-in-Trust could be appropriate for funding many programmes, while organizations such as the International Council of Scientific Unions might represent US interests in others. But even if UNESCO's science programmes are treated well in the budget for fiscal year 1986, international organizations may want some guarantees that US funds they

The US National Commission on UNESCO recently passed a resolution expressing "regret" at the withdrawal decision and urged the State Department to restore the commission's full-time staff to monitor further reforms at UNESCO. Gregory Newell, assistant secretary of international organization affairs at the State Department, acknowledged that the United States might consider rejoining the organization if its complaints were met, but hinted that the United States would consider pulling out of other international organizations that were damaging US interests or were not meeting their objectives. administer will not suddenly dry up.

\section{Neutron source A shoestring operation}

BRITAIN's spallation neutron source (SNS), which will soon be the world's most intense source of low-energy neutrons, produced its first test beams of neutrons last month at one four-thousandth of the design intensity. Full operation is due to start in April, but, says Dr Geoff Manning, director of the Rutherford-Appleton Laboratory where SNS is based, "at present we don't have enough money to run next year'".

Running costs will be $£ 10$ million, he estimates, compared with a capital cost of $£ 50$ million of new money. But there is only $£ 8$ million in the kitty. The difference is equal to the expected electricity bill for operating SNS in 1985.

Nevertheless SNS will run - but in somewhat straitened circumstances. The machine and its four existing instruments, which worked perfectly in the test run, are already two years late as a result of funding delays, and is now in serious danger of under-exploitation. SNS is designed to run 20 instruments on 18 beam-lines, and to provide facilities for "several hundred" UK university and industrial scientists. But exactly when that maximum will be reached is unclear. The Science and Engineering Research Council has been actively seeking foreign participation and support, and has so far succeeded only with India, whose Bhabha Institute in Bombay has provided one of the four existing instruments.

There had been British hopes that West Germany would help, but faced with no British money for HERA (a protonelectron collider now under construction in Hamburg), nor for the European Synchrotron Radiation Source, nor any British commitment to a next-generation neutron spallation source planned in Germany for the $1990 \mathrm{~s}$, it is perhaps not surprising that the German government has been lukewarm in contributing to SNS. There will be one German experiment at SNS - a neutrino detector for experiments on masses and mixing of neutrino types.

SNS's main role, as was evidenced by the test experiments last week, involves neutrons as diffractive probes of atomic, molecular and material structures of liquid and solid-state matter. In this the use of neutrons is similar to that of $\mathrm{X}$ rays, with the exception that the energy of a neutron of a given (de Broglie) wavelength is much lower than that of an X ray of the same wavelength - thus allowing greater intensities without damage to the sample. Neutrons interact principally with nuclei, rather than the electronic structure of a material, thus providing complementary information to X-ray (and synchrotron radiation) investigations.

Robert Walgate 